\title{
Anti-nociceptive and desensitizing effects of olvanil on capsaicin-induced thermal hyperalgesia in the rat
}

\author{
Mohammad Alsalem ${ }^{1 *}$, Paul Millns², Ahmad Altarifi ${ }^{3}$, Khalid El-Salem $^{3}$, Victoria Chapman ${ }^{2,4}$ and David A. Kendall ${ }^{2}$
}

\begin{abstract}
Background: Olvanil (NE 19550) is a non-pungent synthetic analogue of capsaicin, the natural pungent ingredient of capsicum which activates the transient receptor potential vanilloid type-1 (TRPV1) channel and was developed as a potential analgesic compound. Olvanil has potent anti-hyperalgesic effects in several experimental models of chronic pain. Here we report the inhibitory effects of olvanil on nociceptive processing using cultured dorsal root ganglion (DRG) neurons and compare the effects of capsaicin and olvanil on thermal nociceptive processing in vivo; potential contributions of the cannabinoid $\mathrm{CB}_{1}$ receptor to olvanil's anti-hyperalgesic effects were also investigated.
\end{abstract}

Methods: A hot plate analgesia meter was used to evaluate the anti-nociceptive effects of olvanil on capsaicin-induced thermal hyperalgesia and the role played by $\mathrm{CB}_{1}$ receptors in mediating these effects. Single cell calcium imaging studies of DRG neurons were employed to determine the desensitizing effects of olvanil on capsaicin-evoked calcium responses. Statistical analysis used Student's t test or one way ANOVA followed by Dunnett's post-hoc test as appropriate.

Results: Both olvanil (100 nM) and capsaicin (100 nM) produced significant increases in intracellular calcium concentrations $\left[\mathrm{Ca}^{2+}\right]_{\mathrm{i}}$ in cultured DRG neurons. Olvanil was able to desensitise TRPV1 responses to further capsaicin exposure more effectively than capsaicin. Intraplantar injection of capsaicin (0.1, 0.3 and $1 \mu \mathrm{g}$ ) produced a robust TRPV1dependant thermal hyperalgesia in rats, whilst olvanil $(0.1,0.3$ and $1 \mu \mathrm{g})$ produced no hyperalgesia, emphasizing its lack of pungency. The highest dose of olvanil significantly reduced the hyperalgesic effects of capsaicin in vivo. Intraplantar injection of the selective cannabinoid $\mathrm{CB}_{1}$ receptor antagonist rimonabant $(1 \mu \mathrm{g})$ altered neither capsaicin-induced thermal hyperalgesia nor the desensitizing properties of olvanil, indicating a lack of involvement of $\mathrm{CB}_{1}$ receptors.

Conclusions: Olvanil is effective in reducing capsaicin-induced thermal hyperalgesia, probably via directly desensitizing TRPV1 channels in a $\mathrm{CB}_{1}$ receptor-independent fashion. The results presented clearly support the potential for olvanil in the development of new topical analgesic preparations for treating chronic pain conditions while avoiding the unwanted side effects of capsaicin treatments.

Keywords: Transient receptor potential vanilloid type 1, Cannabinoid receptor 1, Pungency and pain

\footnotetext{
*Correspondence: m_alsalem@ju.edu.jo

'Department of Anatomy and Histology, Faculty of Medicine, The University

of Jordan, Amman 11942, Jordan

Full list of author information is available at the end of the article
} 


\section{Background}

TRPV1 (transient receptor potential vanilloid type 1) is a chemically-gated non-specific cation channel with high calcium permeability [1], which integrates a range of painful stimuli including noxious heat $\left(>43^{\circ} \mathrm{C}\right)$ [2] and low $\mathrm{pH}$ [3] and which responds to pungent compounds, such as capsaicin $[2,4]$. TRPV1 is widely distributed throughout the central [5] and peripheral nervous systems [6]. It is well established that TRPV1 is a key molecule involved in the progress of many chronic pain conditions such as those associated with inflammation, cancer and neuropathy [7-10]. As a consequence, TRPV1 is viewed as a prime target for pharmacological intervention to control pain. Although the development of TRPV1 antagonists has been a logical step forward for developing new analgesics, their clinical benefit is limited by unwanted side effects including effects on core body temperature [11-13].

The increase in intracellular calcium concentration $\left(\left[\mathrm{Ca}^{2+}\right]_{\mathrm{i}}\right)$ mediated by TRPV1 is essential to induce neurotransmitter release from the primary afferent fibres. However, elevation of $\left[\mathrm{Ca}^{2+}\right]_{\mathrm{i}}$ through TRPV1 activation leads to desensitization of the channel, probably through calcium-dependent mechanisms including $\mathrm{Ca}^{2+} /$ calmodulin and the $\mathrm{Ca}^{2+}$-sensitive phosphatase calcineurin $[14,15]$. Desensitization of TRPV1, which occurs after the calcium entry, provides a feedback mechanism to regulate calcium homeostasis and is the basis of the use of TRPV1 agonists as analgesics as an alternative approach to TRPV1 antagonism. Indeed, topical preparations containing low concentrations of capsaicin have long been used as over-the-counter remedies for pain.

Clinical trials have demonstrated that capsaicin is effective in alleviating pain associated with osteoarthritis [16], and a synthetic, orally active isomer of capsaicin, civamide, was reported to significantly reduce cluster headache [17] and migraine headache [18]. Highconcentration topical capsaicin (8\% patch; Qutenza ${ }^{\circ}$ ) is licensed in the EU to treat neuropathic pain in nondiabetic patients, and in the US to treat peripheral herpetic neuralgia. Treatment can give rise to a long-lasting effect, which has been termed 'defunctionalisation', probably owing to a number of different effects that, together, overwhelm neuronal homeostasis, leading to reversible degeneration of nerve terminals [19]. However, the use of TRPV1 agonists like capsaicin is hindered by the initial sharp and burning sensation, referred to as pungency which requires patches to be available for use only by specialist healthcare workers and needs pre-treatment with local anesthetic.

Development of non-pungent capsaicin analogues such as olvanil, palvanil and arvanil with retention of analgesic properties could be of significant clinical value. Previous studies explored differences between pungent and non-pungent TRPV1 agonists, and proposed various hypotheses to explain the translation of these differences in in vivo pungency. Interestingly, none of the previous reports evaluated the effects of the non-pungent TRPV1 agonist olvanil on the capsaicin-evoked calcium responses in isolated DRG neurons, which may have an important physiological relevance in particular to TRPV1 desensitization and the subsequent neurotransmitter release. Furthermore, the contribution of $\mathrm{CB}_{1}$ cannabinoid receptors to the analgesic effects of olvanil in vivo remains unclear, as the previous reports were focused solely on in vitro studies using cell lines. The aim of the current study was to fill in these gaps and test the anti-hyperalgesic effects of olvanil and to further study the potential role for cannabinoid receptors in mediating these analgesic effects. To address the mechanism of the desensitizing effects of olvanil on the capsaicin-evoked hyperalgesia, calcium responses in isolated DRG neurons were also evaluated.

\section{Methods \\ Animals}

Calcium imaging experiments used adult male Sprague Dawley rats (180-200 g, Charles River UK). Rats were group housed in the Biomedical Services Unit (University of Nottingham) in a temperature controlled environment $22 \pm 1{ }^{\circ} \mathrm{C}$ at $12 \mathrm{~h}$ : $12 \mathrm{~h}$ light: dark cycle. Behavioural experiments used adult male albino rats (180-200 g, The University of Jordan laboratories). Procedures were approved by the University of Nottingham Ethical Review Committee and by the scientific research committee at the University of Jordan. Experiments were carried out in accordance with the Animal (Scientific Procedure) Act 1986 and International Association for the Study of Pain guidelines.

\section{Calcium imaging of dorsal root ganglion neurons}

A total of 16 rats, killed by $\mathrm{CO}_{2}$ overdose, were used for the calcium imaging studies. Spinal columns were removed and dorsal root ganglia (DRGs) neurons were collected [20]; cell preparation and culture were as described previously [21, 22].

Cells were washed three times with calcium imaging buffer $\left(\mathrm{NaCl}, 145 \mathrm{mM} \mathrm{KCl}, 5 \mathrm{mM} ; \mathrm{CaCl}_{2}, 2 \mathrm{mM}\right.$; $\mathrm{MgSO}_{4} .7 \mathrm{H}_{2} \mathrm{O}, 1 \mathrm{mM}$; HEPES, $10 \mathrm{mM}$; glucose, $10 \mathrm{mM}$; $\mathrm{pH}, 7.4)$. Then cells were loaded with $5 \mu \mathrm{l}$ of Fura2-AM in $895 \mu \mathrm{l}$ of calcium buffer with $100 \mu \mathrm{l}$ of fetal calf serum (FCS) and incubated for $30 \mathrm{~min}$ in the dark. Cells were washed with calcium buffer and left for at least 15 min prior to imaging. $\left[\mathrm{Ca}^{2+}\right]_{\mathrm{i}}$ was measured as the ratio of peak fluorescence emission intensities (measured at $500 \mathrm{~nm}$ ) at excitation wavelengths of $340 \mathrm{~nm}$ and $380 \mathrm{~nm}$, respectively, using an Andor IQ imaging system and expressed as changes in relative fluorescence units 
$(\Delta \mathrm{RU})$. Coverslips were fixed to a Perspex chamber using vacuum grease, and the DRG neurons were suprafused with calcium buffer at a rate of $2 \mathrm{ml} / \mathrm{min}$. All drugs were applied by suprafusion in calcium buffer.

\section{Effects of olvanil on capsaicin-evoked calcium responses}

Experiments were designed so that DRG cells were not exposed to capsaicin more than three times. A standard protocol was followed in which DRG cells were exposed to capsaicin $(100 \mathrm{nM})$ for $1 \mathrm{~min}$ followed by a $45 \mathrm{~min}$ wash-out period. Olvanil (100 nM) was then suprafused for $1 \mathrm{~min}$ followed by another $45 \mathrm{~min}$ of wash-out. Finally, cells were re-exposed to capsaicin $(100 \mathrm{nM}$ for $1 \mathrm{~min}$ ) followed by $45 \mathrm{~min}$ of wash-out. This protocol was followed based on the observation that the majority of capsaicin-evoked calcium responses returned to baseline values after a $45 \mathrm{~min}$ wash-out period, as previously reported [22, 23].

To determine whether TRPV1 desensitization could have been a confounding factor, parallel control experiments were conducted in which DRG cells were challenged three times with capsaicin, using the same timing schedule as described above (capsaicin exposure separated by a $45 \mathrm{~min}$ wash-out period). A depolarizing concentration of $\mathrm{KCl}(60 \mathrm{mM})$ was applied at the end of each experiment to confirm neuronal responsiveness. $\mathrm{KCl}$ responding cells that had a peak $340: 380 \mathrm{~nm}$ ratio of more than 0.10 and were at least 0.2 fluorescence units above the baseline were included in the analysis. Peak ratios were calculated by subtracting the baseline ratio from the ratio obtained during drug suprafusion $(\Delta R U$; ratio units difference). Results are expressed as a percentage of the peak response evoked by the first capsaicin application and presented as mean \pm SEM. For each of the drug application protocols performed for calcium imaging, DRG cells were collected from three to five rats, and at least one coverslip of DRG cells from each rat was used for each experiment.

\section{Hot plate testing}

Rats were placed individually on a hot plate analgesia meter (Columbus instruments, USA) maintained at a constant temperature of $55 \pm 0.1{ }^{\circ} \mathrm{C}$ after observing them for $5 \mathrm{~min}$ in the cage [24]. The paw withdrawal latency (PWL) was recorded as the time taken to exhibit distinct pain behaviour either by hindpaw licking or hindpaw flicks (whichever occurred first). Rats that did not respond within $30 \mathrm{~s}$ were removed from the hot plate to prevent tissue damage [25].

\section{Capsaicin-induced thermal hyperalgesia}

After determining the baseline latencies, rats received intraplantar injections of capsaicin $(0.1,0.3$ and $1 \mu \mathrm{g}$ in $100 \mu \mathrm{L}$ of PBS or vehicle) under brief ether anesthesia.
Thermal paw withdrawal latencies (PWL) were then determined at 10, 30 and 100 min after capsaicin injection. Data are presented as percentages of the baseline PWL (\% PWL = Observed PWL / Baseline PWL × 100).

\section{Pharmacological treatments}

For the assessments of the effects of different drugs on the capsaicin-induced thermal hyperalgesia, olvanil (0.1, 0.3 and $1 \mu \mathrm{g}$ ), $1 \mu \mathrm{g}$ capsazepine, $1 \mu \mathrm{g}$ rimonabant (a selective cannabinoid $\mathrm{CB}_{1}$ receptor antagonist) or olvanil $(0.3 \mu \mathrm{g})$ plus rimonabant $(1 \mu \mathrm{g})$ were injected $15 \mathrm{~min}$ prior to capsaicin; all drugs were dissolved in $50 \mu \mathrm{l}$ of PBS, except capsaicin which was dissolved in $100 \mu \mathrm{l}$ of PBS as described above. The maximum hyperalgesic effect of capsaicin was observed 10 min post-injection; therefore, all nociceptive testing was done $10 \mathrm{~min}$ following capsaicin administration.

\section{Drugs}

Capsaicin, capsazepine, olvanil and rimonabant were purchased from Tocris Bioscience (UK). Drugs were initially dissolved in ethanol (100\%) to form a stock solution (capsaicin $1 \mathrm{mM}$, capsazepine $10 \mathrm{mM}$, olvanil $10 \mathrm{mM}$ and rimonabant $10 \mathrm{mM}$ ), then diluted in phosphate-buffered saline (PBS). Final ethanol concentrations in the solutions used in the present study did not exceed $0.1 \%$.

\section{Data analysis}

Calcium imaging data are presented as a means \pm SEM of percentage of the peak responses evoked by the first capsaicin application, and statistical analysis (Prism 5, GraphPad Software Inc., La Jolla, CA, USA) used Student's t-tests. For the studies measuring capsaicin-induced thermal hyperalgesia data are presented as means \pm SEM of percentages of the baseline PWL (\% PWL = Observed PWL/ Baseline PWLX 100), and statistical analysis (Prism 5, GraphPad) used one way ANOVA test followed by Dunnett's post-hoc test as appropriate.

\section{Results}

\section{Capsaicin-induced thermal hyperalgesia}

In the in vivo behavioral studies, intra-plantar injection of capsaicin produced a dose- and time-dependent hyperalgesia (Fig. 1). At all doses tested, the peak hyperalgesic effect was at 10 min post-injection, with the paw withdrawal latencies returning to baseline levels by $100 \mathrm{~min}$ post-injection.

To test whether the hyperalgesic effects of capsaicin were TRPV1 receptor-mediated, the TRPV1 receptor antagonist capsazepine $(1 \mu \mathrm{g})$ was injected into the ipsilateral hindpaw of the rat $15 \mathrm{~min}$ prior to capsaicin. Capsazepine significantly attenuated capsaicin-induced thermal hyperalgesia (Fig. 2). 


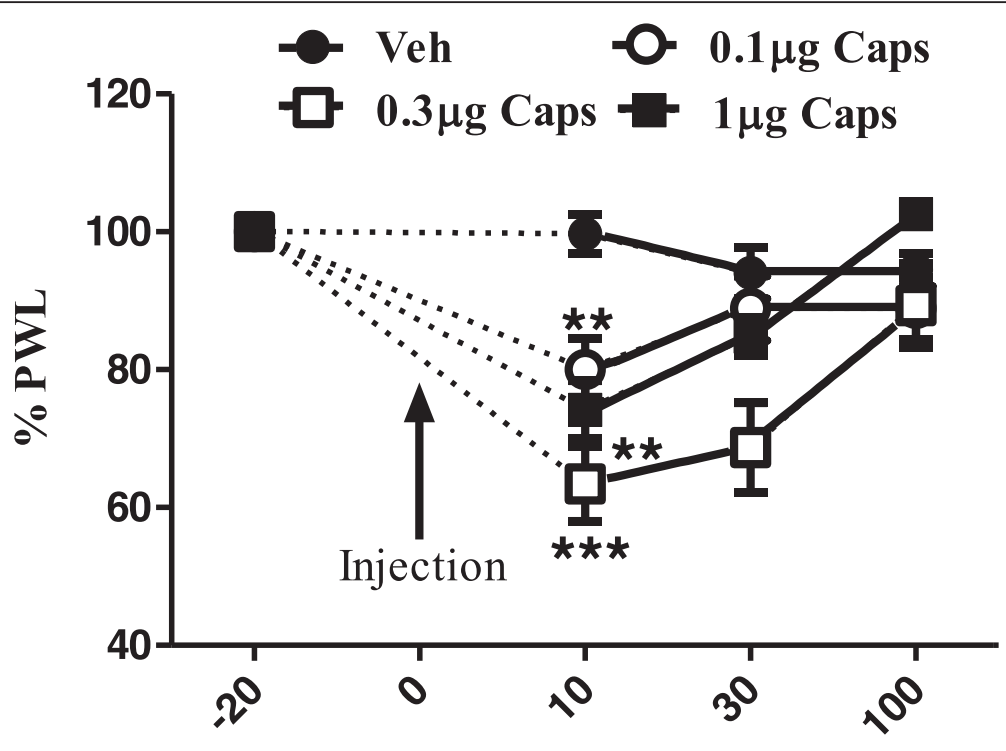

Time (min) post-capsaicin administration

Fig. 1 Effects of intraplantar injection of different doses of capsaicin on thermal paw withdrawal latency. Data are expressed as mean \pm SEM of $\%$ PWL and analyzed using one way ANOVA test followed by Dunnett's post-hoc, all doses of capsaicin were compared to vehicle at 10 min after injection ${ }^{* *} P<0.01,{ }^{* *} P<0.001, n=7$ rats per group)

To test whether an endogenous cannabinoid tone modulates the capsaicin-evoked thermal hyperalgesia, the selective $\mathrm{CB}_{1}$ antagonist rimonabant $(1 \mu \mathrm{g})$ was injected into the ipsilateral hindpaw of the rat 15 min prior to capsaicin. Unlike capsazepine, rimonabant had no significant effect on capsaicin-induced thermal hyperalgesia (Fig. 3).
In contrast to capsaicin, intra-plantar injection of olvanil (0.1, 0.3 and $1 \mu \mathrm{g}$ ) did not alter thermal nociceptive thresholds, confirming its lack of pungency (Fig. 4). Interestingly, intra-plantar injection of olvanil $(1 \mu \mathrm{g})$ significantly attenuated capsaicin-evoked thermal hyperalgesia (Fig. 5). In order to evaluate the possible role of $\mathrm{CB}_{1}$

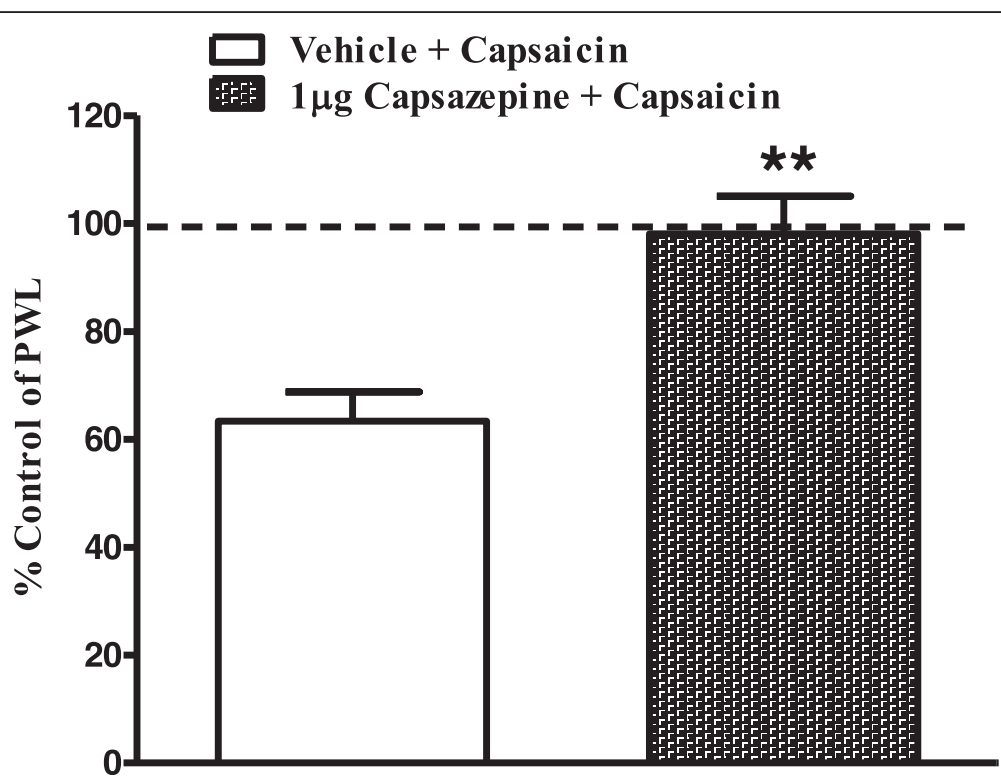

Fig. 2 Effects of intraplantar injection of capsazepine $(1 \mu \mathrm{g})$ on capsaicin-induced thermal hyperalgesia. Rats received intraplantar injections of capsazepine, or vehicle 15 min prior to capsaicin. Data are expressed as mean \pm SEM of \%PWL and analyzed using Student's $t$ test, ${ }^{* *} P<0.005, n=7$ rats per group) 


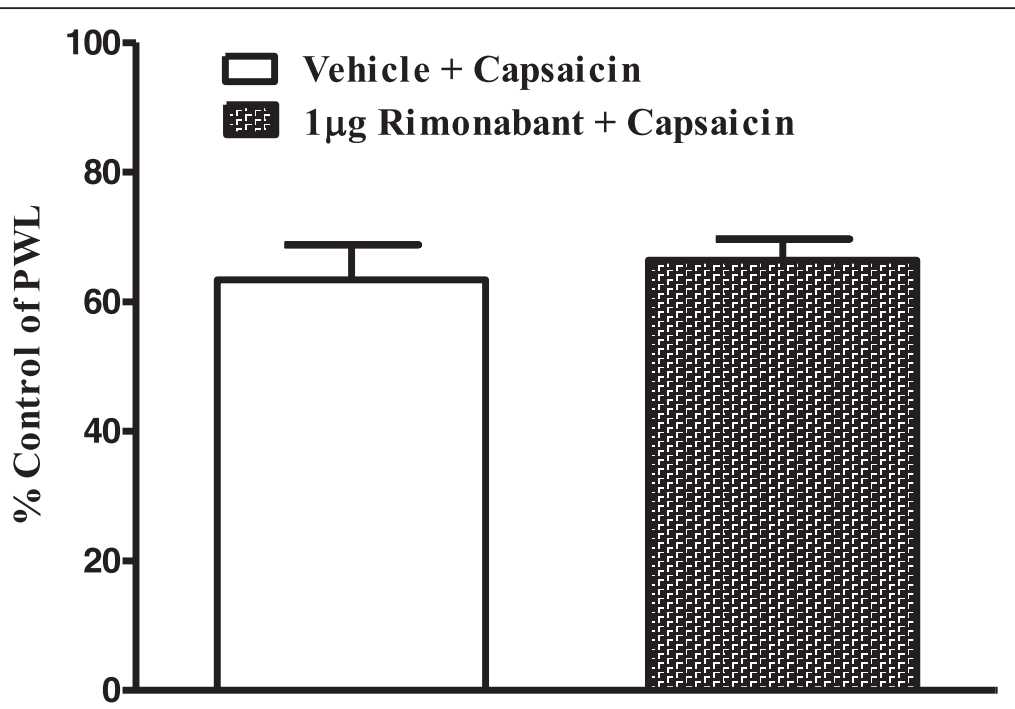

Fig. 3 Effects of intraplantar injection of rimonabant $(1 \mu \mathrm{g})$ on capsaicin-induced thermal hyperalgesia. Rats received intraplantar injections of rimonabant or vehicle 15 min prior to capsaicin. Data are expressed as mean \pm SEM of \%PWL and analyzed using Student's t test $(n=7$ rats per group)

receptors in these inhibitory effects of olvanil, $1 \mu \mathrm{g}$ rimonabant was co-administered with olvanil, The $\mathrm{CB}_{1}$ antagonist did not significantly alter the inhibitory effect of olvanil on capsaicin-evoked thermal hyperalgesia (Fig. 5).

Olvanil attenuates capsaicin-evoked calcium responses Capsaicin produced a robust increase in $\left[\mathrm{Ca}^{2+}\right]_{\mathrm{i}}$ compared to basal $(0.625 \pm 0.03 \Delta R U, n=76$ neurons, Fig. 6). To ensure that studies were not compromised by desensitization of TRPV1, effects of repeated application of capsaicin were studied. A second capsaicin challenge in the presence of vehicle $(0.01 \%$ ethanol in PBS) evoked a calcium response of $80.8 \pm 2.3 \%$ of the preceding capsaicin-evoked response. A third capsaicin challenge evoked a calcium response of $77.2 \pm 2.2 \%$ of the first capsaicin-evoked response. Statistical analysis revealed no significant differences between the second and third exposures to capsaicin (Fig. 7).

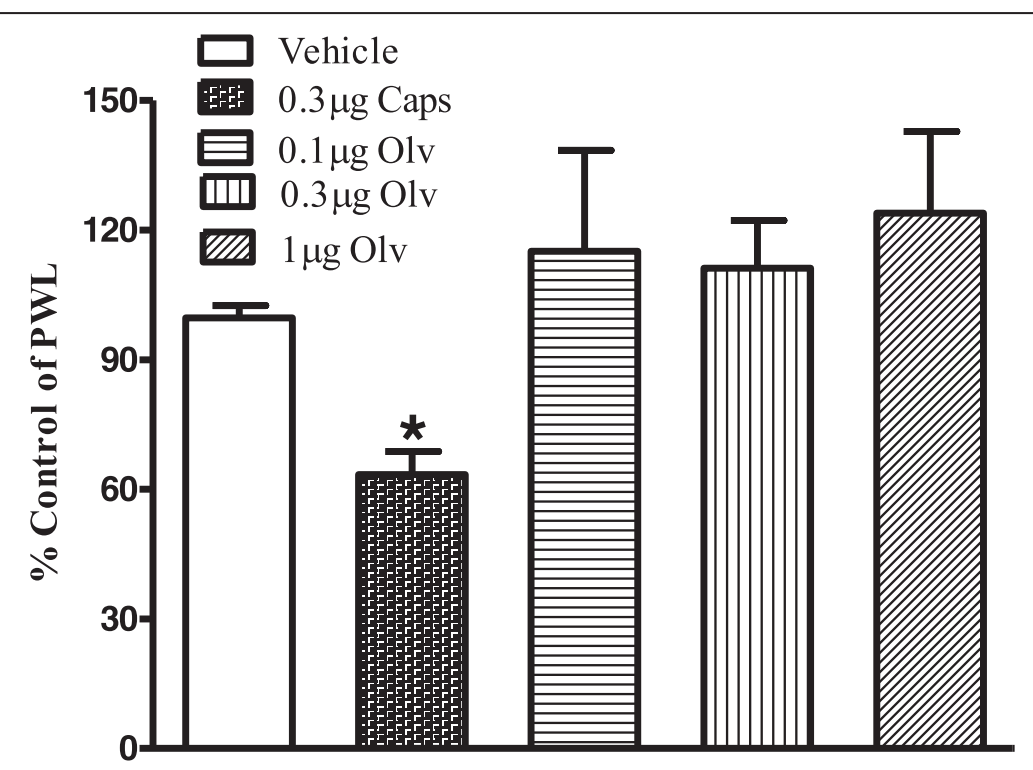

Fig. 4 Effects of intraplantar injection of capsaicin $(0.3 \mu \mathrm{g})$, olvanil $(0.1,0.3$ and $1 \mu \mathrm{g})$, or vehicle on paw withdrawal latency. Data are expressed as mean \pm SEM of $\%$ PWL and analyzed using one way ANOVA test followed by Dunnett's post-hoc, all treatments were compared to vehicle at 10 min after injection ( ${ }^{*} P<0.05, n=7$ rats per group) 


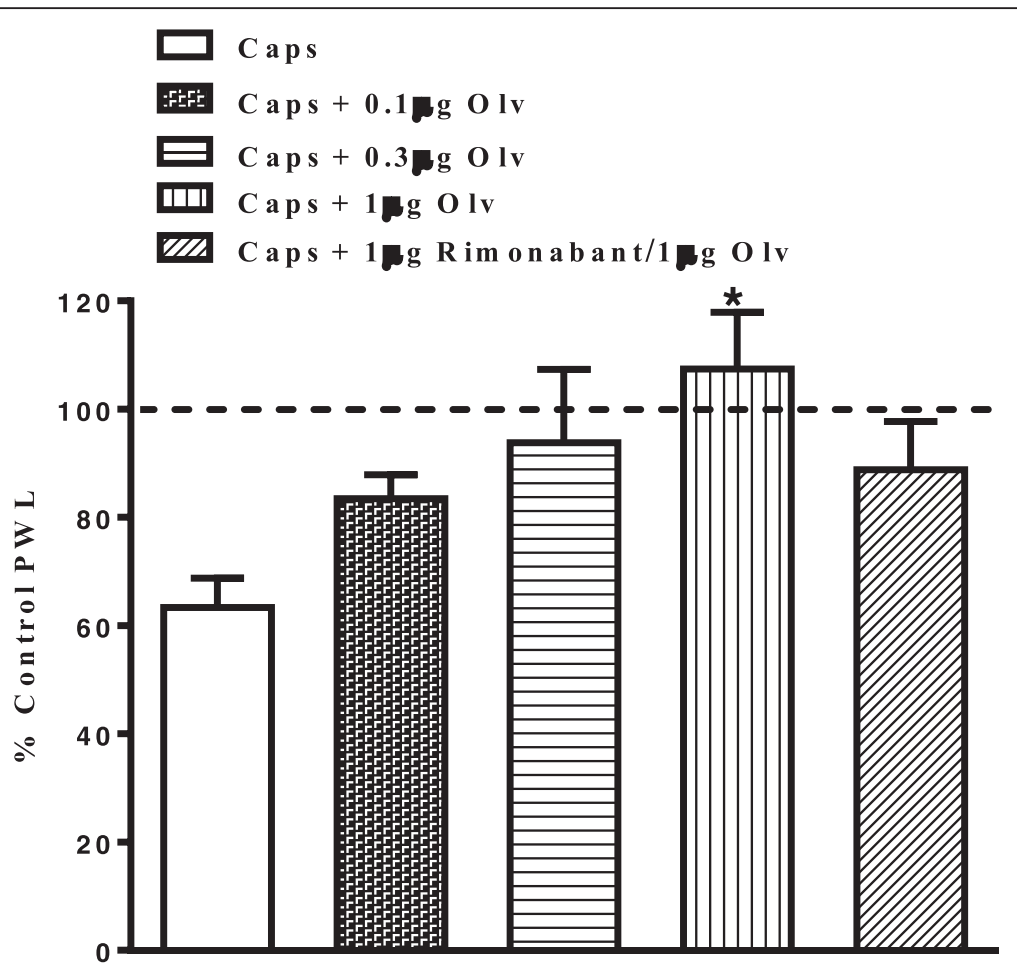

Fig. 5 Effects of intraplantar injection of various doses of olvanil and rimonabant $(1 \mu \mathrm{g})$ on capsaicin-induced thermal hyperalgesia. Rats received intraplantar injection of olvanil (Olv; $0.1,0.3$ and $1 \mu \mathrm{g}$ ) or a combination of $0.3 \mu \mathrm{g}$ olvanil/1 $\mu \mathrm{g}$ rimonabant or vehicle 15 min prior to capsaicin (Caps). Data are expressed as mean \pm SEM of $\%$ PWL and analyzed using one way ANOVA test followed by Dunnett's post-hoc, different treatments were compared to vehicle at 10 min after injection ( $* P<0.05, n=7$ rats per group)

Olvanil produced a robust increase in $\left[\mathrm{Ca}^{2+}\right]_{\mathrm{i}}$ over basal $(0.566 \pm 0.04 \Delta \mathrm{RU}, n=128$ neurons). Pre-exposing the cells to the potent selective TRPV1 antagonist $5^{\prime}$-iodoresiniferatoxin $(1 \mu \mathrm{M})$ completely blocked both capsaicin and olvanil-evoked calcium responses (data not shown). Statistical analysis revealed no significant differences between capsaicin-evoked calcium responses $(0.625 \pm 0.03 \Delta \mathrm{RU}, n=$ 76 neurons) and olvanil-evoked calcium responses (0.566 \pm $0.04 \Delta \mathrm{RU}, n=128$ neurons, $P$ value $=0.26)$ at the same concentration (100 nM); however, capsaicin-evoked calcium responses were significantly inhibited in cells pre-treated with olvanil $(31.6 \pm 2.6 \%$ of the first capsaicinevoked calcium response) compared to vehicle pretreatment $(77.2 \pm 2.2 \%$, Figs. 6 and 7$)$.

In order to investigate whether the ability of olvanil to reduce the subsequent effects of capsaicin was simply due to a persistent desensitization of TRPV1, we studied the effect of repeated applications of olvanil on the DRG neurons. A second application of olvanil in the presence of vehicle $(0.01 \%$ ethanol) evoked a calcium response of $60.2 \pm 1.6 \%$ of the preceding olvanil-evoked calcium response (Fig. 8).

\section{Discussion}

In the present study we investigated the antihyperalgesic effects of olvanil in a model of thermal hyperalgesia which employed capsaicin as an agent that directly activates TRPV1 on primary sensory neurons. In parallel, by means of single cell ratiometric calcium imaging experiments, we investigated TRPV1 receptor desensitization following exposure to olvanil.

In agreement with previous reports [26-28], intraplantar injection of capsaicin produced a robust thermal hyperalgesia in a TRPV1-dependent manner. After confirming the lack of pungency of olvanil using the same model, we showed that olvanil inhibited the hyperalgesic effects of intraplantar injection of capsaicin. Based on previous reports suggesting that olvanil may behave as a $\mathrm{CB}_{1}$ receptor agonist [29] we explored the mechanisms that underlie the anti-hyperalgesic effects of olvanil by evaluating the potential role of the $\mathrm{CB}_{1}$ receptor in mediating these effects of olvanil. The hypothesis that other receptors activated by olvanil, but not capsaicin, such as the cannabinoid $\mathrm{CB}_{1}$ [29] may account for the differences between these agonists in terms of pungency and could conceivably explain the antihyperalgesic effects of olvanil. However, the $\mathrm{CB}_{1}$ antagonist rimonabant did not alter the analgesic effects of olvanil, excluding a role for $\mathrm{CB}_{1}$ in mediating these effects in vivo. This is in spite of previous in vitro studies using cell lines that reported olvanil binding to $\mathrm{CB}_{1}$ receptors and inhibition of adenylyl cyclase leading to reduction of cAMP levels in N18TG2 neuroblastoma cells [30]. In addition, 

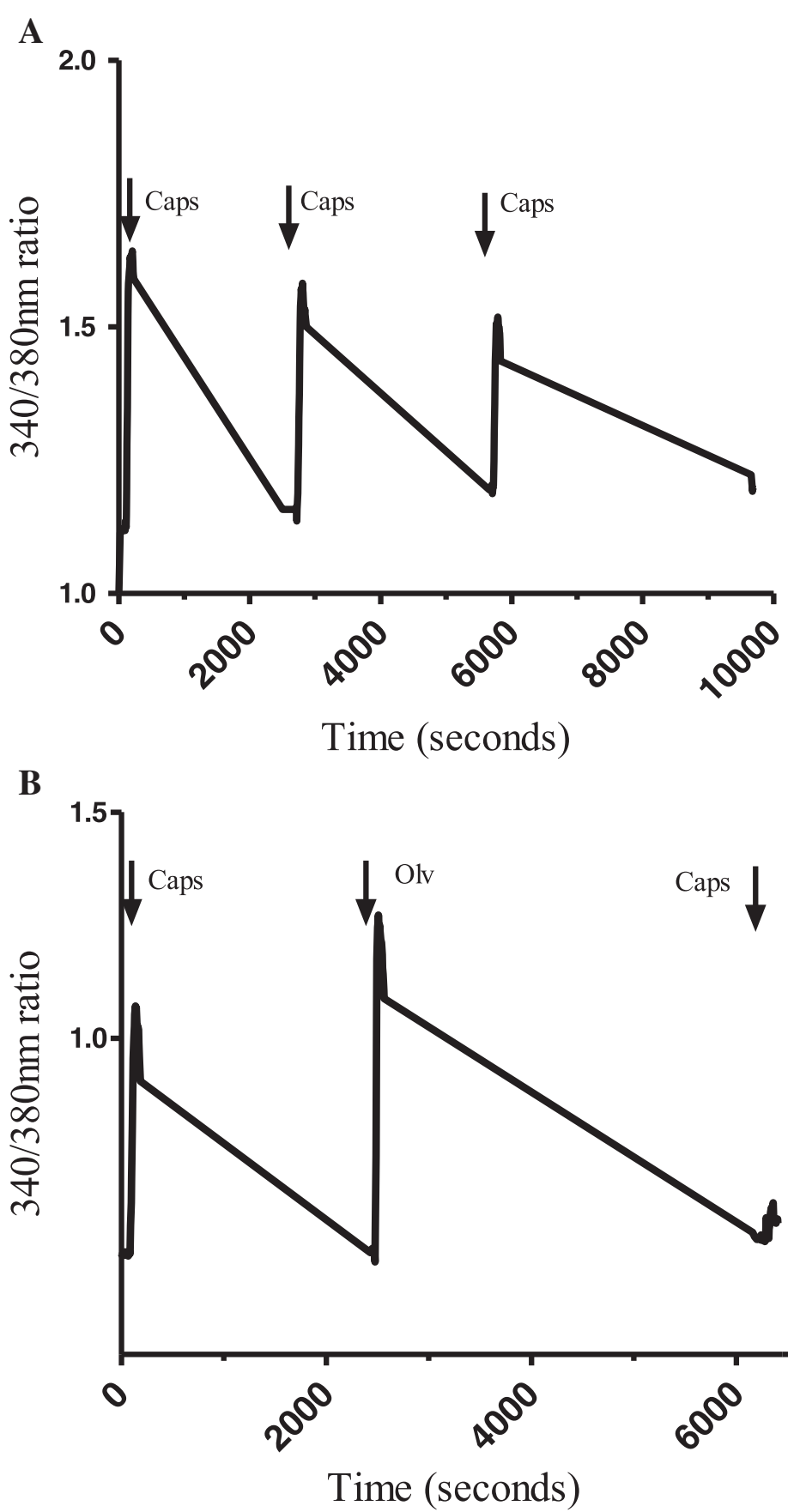

Fig. 6 Representative traces illustrating changes in 340/380 nm ratios in DRG cells responding to capsaicin and olvanil. a The cell was suprafused with capsaicin (100 nM for $1 \mathrm{~min}$ ) three times separated by $45 \mathrm{~min}$ of wash-out with calcium buffer. $\mathbf{b}$ The cell was exposed to capsaicin (100 nM) for 1 min, 45 min later, olvanil (100 nM) was applied for 1 min followed by another 45 min of wash-out. Finally, the cell was exposed again to capsaicin (100 nM for $1 \mathrm{~min})$ followed by $45 \mathrm{~min}$ of wash-out

olvanil has been shown to inhibit transport of the endocannabinoid anandamide into RBL-2H3 cells and to inhibit the hydrolysis of anandamide by FAAH, the principal endocannabinoid metabolizing enzyme [29,31]. The inability of rimonabant to attenuate the analgesic effects of olvanil suggests that activation of the endocannabinoid system, which has a well-documented inhibitory effect on sensory nerve function and TRPV1 activity, is unlikely to account for the differences between the pungency of olvanil and capsaicin, and, to the best of our knowledge, this is the first report evaluating the contribution of $\mathrm{CB}_{1}$ receptors to the effects of olvanil in vivo. In a recent study evaluating analgesic 


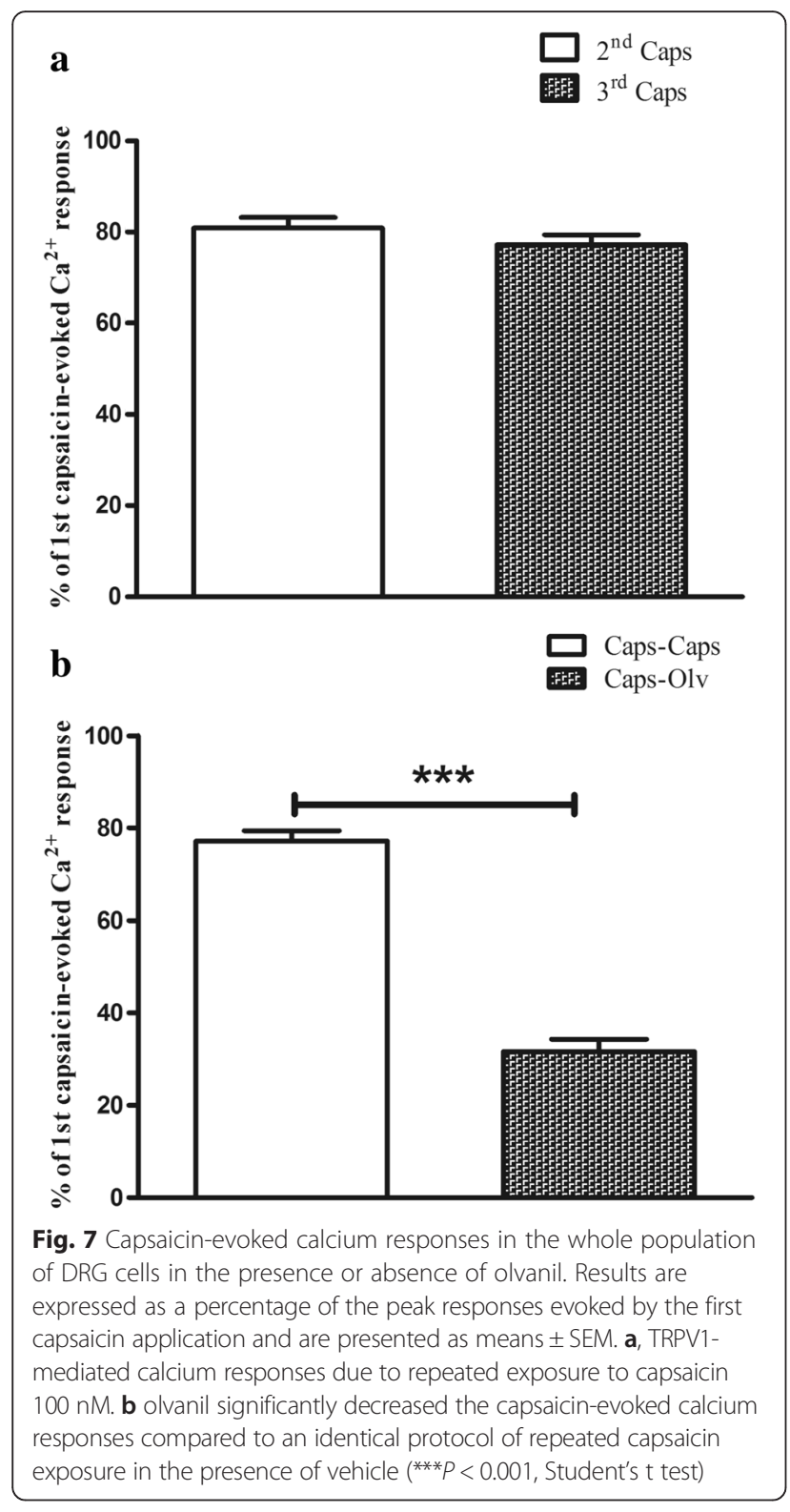

effects of olvanil on migraine, olvanil reduced spontaneous and stimulus-induced activity within the trigeminocervical complex; whereas it had no effect on cortical spreading depression; an effect mediated by both TRPV1 and $\mathrm{CB}_{1}$ [32].

To further explore the mechanisms that could mediate the anti-hyperalgesic effects of olvanil, we studied its effects on the capsaicin-evoked calcium responses in isolated DRG neurons. Despite both olvanil and capsaicin producing a robust increase in $\left[\mathrm{Ca}^{2+}\right]_{\mathrm{i}}$ in cultured dorsal root ganglion cells, olvanil was more effective than capsaicin at producing a desensitisation of TRPV1 to further capsaicin exposure. This finding along with a similar finding that the non-pungent capsaicin analogue palvanil produced a greater desensitising effect of TRPV1 compared to capsaicin [33], suggests that the desensitisation of the TRPV1 channel is not only dependant on the amount of agonist-stimulated calcium influx [34, 35], but also on the type of agonist applied. In line with this proposal, $\mathrm{Xu}$ and co-workers (2005) have shown that camphor, the active ingredient of many traditional balms and liniments, desensitizes TRPV1 in a calcium-independent fashion by activating TRPV1 via channel regions distinct from those affected by capsaicin [36]. Differences in the lipophilicity of the non-pungent TRPV1 agonists were previously suggested to explain the variation between them in vivo, in which highly lipophilic compounds were proposed to cause only a small $\mathrm{Ca}^{2+}$ influx via TRPV1 expressed in the plasma membrane, but not to be able to activate TRPV1 in the endoplasmic reticulum, in contrast to capsaicin (less lipophilic) which can activate both [37]. This observation is unlikely to explain the differences between olvanil and capsaicin responses in the present study as both induced similar calcium responses in DRG cells. This conclusion is supported by the finding that piperine, a pungent TRPV1 agonist causes a more marked desensitisation of TRPV1 compared to capsaicin even in a calcium-free medium [38]. Both piperine and capsaicin produce calcium influx in DRG cells [39], yet they do not cause the same neuroinflammatory peptides to be released. Capsaicin induces the release of substance $\mathrm{P}$, serotonin and cholecystokinin, whereas piperine induces the release of substance P but not serotonin or cholecystokinin [40]. These differences in neurotransmitter release by different TRPV1 agonists may contribute to the differences in effects of olvanil and capsaicin in vivo. This concept is supported by a previous study showing that capsaicin induces a marked release of calcitonin gene related peptide (CGRP) while olvanil produces no detectable release of CGRP in rat spinal cord [41]. In agreement with the antihyperalgesic effects of olvanil observed in the present study, olvanil significantly reduced the release of CGRP evoked by depolarizing $\mathrm{K}^{+}$stimulus [41]. These studies and the present findings clearly question the correlation between the calcium signals evoked by the TRPV1 agonists and their subsequent physiological effects.

In spite of the structural similarity between olvanil and capsaicin which suggests a similar mechanism of action, multiple agonist binding sites for these agonists could explain the differences observed between their responses in vivo, especially when considering the fact that TRPV1 is likely to present as a tetrameric complex [42]; therefore, different agonists could recruit more TRPV1 subunits or have alternative binding sites on the TRPV1 channel complex.

One limitation of our calcium imaging experiments is that they were performed on the cell bodies of primary afferent neurons (as in the majority of the previous studies using DRG) as axons are removed in the isolation 


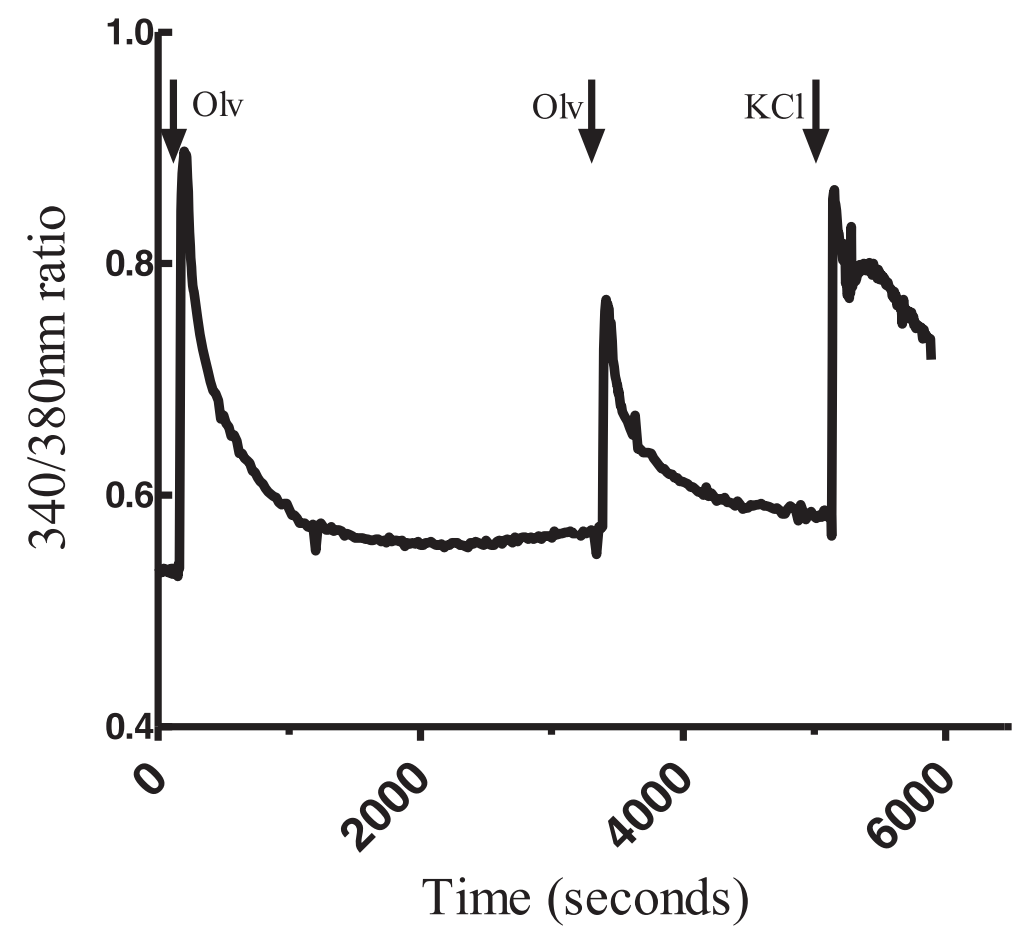

Fig. 8 Representative traces illustrating changes in 340/380 nm ratios in DRG cells responding to olvanil. The cell was suprafused with olvanil (100 nM for $1 \mathrm{~min}$ ) two times separated by $45 \mathrm{~min}$ of wash-out with calcium buffer. Finally, the cell was exposed to $\mathrm{KCl}$ (60 mM for $1 \mathrm{~min}$ ) followed by 45 min of wash-out

process, raising the possibility that the TRPV1 channels expressed in the cell body have different properties from those expressed in the nerve terminals, as was recently proposed [43]. In this previous study, pungent compounds such as capsaicin and piperine amplified the glutamatergic spontaneous excitatory synaptic transmission in spinal substantia gelatinosa neurons, while olvanil, even at a very high concentration $(10 \mu \mathrm{M})$, had a minimal effect. Thus, it is possible that pungent and nonpungent agonists could have similar effects on the cell body TRPV1 channels but might (in the case of pungent agonists) or might not (in the case of non-pungent agents) be able to generate action potentials, and subsequently nociceptive signals, when applied to TRPV1 expressed on the sensory nerve terminals. This possibility was recently studied in vagal $\mathrm{C}$ - fibres, in which the authors showed that jugular C-fibres have different capacities to transport particular TRPV1 agonists across cell membranes in the nerve terminals to intracellular binding sites, while the effects of different agonists on sensory nerve cell bodies were the same [44]. This undoubtedly needs to be verified in more integrated neuronal preparations in which measurements of $\left[\mathrm{Ca}^{2+}\right]_{\mathrm{i}}$ and applications of different agonists take place in the neuronal processes rather than in isolated DRG cell bodies.

\section{Conclusions}

Olvanil was effective at reducing capsaicin-induced thermal hyperalgesia, likely via directly desensitizing TRPV1. This effect was independent of $\mathrm{CB}_{1}$ receptor activation. Although our findings cannot fully explain the lack of pungency of olvanil, they clearly support the possibility of employing olvanil to develop new topical treatments for a wide range of chronic pain conditions, such as arthritis, while overcoming the unwanted side effects of the currently used capsaicin preparations.

\section{Acknowledgements \\ This work was supported by the deanship of academic research in The University of Jordan.}

\section{Funding}

This work was supported by the deanship of academic research in The University of Jordan.

\section{Availability of data and materials}

Present within the manuscript.

\section{Authors' contributions}

MA carried out the hot plate testing, and drafted the manuscript. PM carried out the calcium imaging study and its analysis. AA participated in the hot plate testing, animal anesthesia and injections. KE participated in the design of the study and performed the statistical analysis. VC participated in the analysis and interpretation of data and revising the manuscript. DAK participated in the design of the study, interpretation of data and revising the manuscript. All authors read and approved the final manuscript. 


\section{Competing interests}

The authors declare that they have no competing interests.

\section{Consent for publication}

Not applicable.

\section{Ethics approval and consent to participate}

Procedures were approved by the University of Nottingham Ethical Review Committee and by the scientific research committee at the University of Jordan. Experiments were carried out in accordance with the Animal (Scientific Procedure) Act 1986 and International Association for the Study of Pain guidelines.

\section{Author details}

'Department of Anatomy and Histology, Faculty of Medicine, The University of Jordan, Amman 11942, Jordan. ${ }^{2}$ School of Life Sciences, University of Nottingham, Queen's Medical Centre, Nottingham NG7 2UH, UK. ${ }^{3}$ Faculty of Medicine, Jordan University of Science and Technology, Irbid 22110, Jordan. ${ }^{4}$ Arthritis Research UK Pain Centre, Nottingham, UK.

Received: 20 January 2016 Accepted: 25 June 2016

Published online: 21 July 2016

\section{References}

1. Caterina MJ, Leffler A, Malmberg AB, Martin WJ, Trafton J, Petersen-Zeitz KR, Koltzenburg M, Basbaum Al, Julius D. Impaired nociception and pain sensation in mice lacking the capsaicin receptor. Science. 2000;288(5464):306-13.

2. Caterina $M$, Schumacher $M$, Tominaga $M$, Rosen $T$, Levine J, Juluis $D$. The capsaicin receptor: a heat-activated ion channel in the pain pathway. Nature. 1997:389:816-24.

3. Tominaga M, Caterina MJ, Malmberg AB, Rosen TA, Gilbert H, Skinner K, Raumann BE, Basbaum Al, Julius D. The cloned capsaicin receptor integrates multiple pain-producing stimuli. Neuron. 1998;21(3):531-43.

4. Szallasi A, Cortright DN, Blum CA, Eid SR. The vanilloid receptor TRPV1: 10 years from channel cloning to antagonist proof-of-concept. Nat Rev Drug Discov. 2007;6(5):357-72.

5. Tóth A, Boczán J, Kedei N, Lizanecz E, Bagi Z, Papp Z, Édes I, Csiba L, Blumberg PM. Expression and distribution of vanilloid receptor 1 (TRPV1) in the adult rat brain. Mol Brain Res. 2005;135(1-2):162-8.

6. Gunthorpe MJ, Szallasi A. Peripheral TRPV1 receptors as targets for drug development: new molecules and mechanisms. Curr Pharm Des. 2008;14(1):32-41.

7. Szabo A, Helyes Z, Sandor K, Bite A, Pinter E, Nemeth J, Banvolgyi A, Bolcskei K, Elekes K, Szolcsanyi J. Role of transient receptor potential vanilloid 1 receptors in adjuvant-induced chronic arthritis: in vivo study using gene-deficient mice. J Pharmacol Exp Ther. 2005:314:111-9.

8. Ghilardi JR, RÃ hrich H, Lindsay TH, Sevcik MA, Schwei MJ, Kubota K, Halvorson KG, Poblete J, Chaplan SR, Dubin AE, Carruthers NI, Swanson D, Kuskowski M, Flores CM, Julius D, Mantyh PW. Selective blockade of the capsaicin receptor TRPV1 attenuates bone cancer pain. J Neurosci. 2005;25(12):3126-31.

9. Christoph T, GrÃ $1 / 4$ nweller A, Mika J, SchÃafer MKH, Wade EJ, Weihe E, Erdmann VA, Frank R, Gillen C, Kurreck J. Silencing of vanilloid receptor TRPV1 by RNAi reduces neuropathic and visceral pain in vivo. Biochem Biophys Res Commun. 2006;350(1):238-43.

10. Davis JB, Gray J, Gunthorpe MJ, Hatcher JP, Davey PT, Overend P, Harries MH, Latcham J, Clapham C, Atkinson K, Hughes SA, Rance K, Grau E, Harper AJ, Pugh PL, Rogers DC, Bingham S, Randall A, Sheardown SA. Vanilloid receptor-1 is essential for inflammatory thermal hyperalgesia. Nature. 2000; 405(6783):183-7.

11. Gavva NR. Body-temperature maintenance as the predominant function of the vanilloid receptor TRPV1. Trends Pharmacol Sci. 2008;29(11):550-7.

12. Wong GY, Gavva NR. Therapeutic potential of vanilloid receptor TRPV1 agonists and antagonists as analgesics: Recent advances and setbacks. Brain Res Rev. 2009;60(1):267-77.

13. Eid SR, Crown ED, Moore EL, Liang HA, Choong KC, Dima S, Henze DA, Kane SA, Urban MO. HC-030031, a TRPA1 selective antagonist, attenuates inflammatory- and neuropathy-induced mechanical hypersensitivity. Mol Pain. 2008:4:48.

14. Rosenbaum T, Gordon-Shaag A, Munari M, Gordon SE. Ca2+/calmodulin modulates TRPV1 activation by capsaicin. J Gen Physiol. 2004;123(1):53-62.
15. Docherty R, Yeats J, Bevan S, Boddeke H. Inhibition of calcineurin inhibits the desensitization of capsaicin-evoked currents in cultured dorsal root ganglion neurones from adult rats. Pflẽ¹/4gers Archiv Eur J Physiol. 1996; 43(0):828-37.

16. Cantillon M, Vause E, Sykes D, Moon A, Hughes S. Safety, tolerability and efficacy of ALGRX 4975 in Osteoarthritis (OA) of the knee. J Pain. 2005:6(3):S39.

17. Saper JR, Klapper J, Mathew NT, Rapoport A, Phillips SB, Bernstein JE, G. for the Intranasal Civamide Study. Intranasal civamide for the treatment of episodic cluster headaches. Arch Neurol. 2002;59(6):990-4.

18. Diamond S, Freitag F, Phillips SB, Bernstein JE, Saper JR. Intranasal civamide for the acute treatment of migraine headache. Cephalalgia. 2000;20(6):597-602.

19. Anand P, Bley K. Topical capsaicin for pain management: therapeutic potential and mechanisms of action of the new high-concentration capsaicin 8\% patch. Br J Anaesth. 2011;107(4):490-502.

20. Lindsay RM. Nerve growth factors (NGF, BDNF) enhance axonal regeneration but are not required for survival of adult sensory neurons. J Neurosci. 1988:8(7):2394-405.

21. Alsalem M, Wong A, Millns P, Arya PH, Chan MSL, Bennett A, Barrett DA, Chapman V, Kendall DA. The contribution of the endogenous TRPV1 ligands 9-HODE and 13-HODE to nociceptive processing and their role in peripheral inflammatory pain mechanisms. Br J Pharmacol. 2013;168(8):1961-74.

22. Millns PJ, Chapman V, Kendall DA. Cannabinoid inhibition of the capsaicininduced calcium response in rat dorsal root ganglion neurones. $\mathrm{Br} J$ Pharmacol. 2001;132(5):969-71.

23. Sagar DR, Smith PA, Millns PJ, Smart D, Kendall DA, Chapman V. TRPV1 and CB1 receptor-mediated effects of the endovanilloid/endocannabinoid $\mathrm{N}$ arachidonoyl-dopamine on primary afferent fibre and spinal cord neuronal responses in the rat. Eur J Neurosci. 2004;20(1):175-84.

24. Woolfe G, Macdonald AD. The evaluation of the analgesic action of pethidine hydrochloride (Demerol). J Pharmacol Exp Ther. 1944;80(3):300-7.

25. Hasani A, Soljakova M, Jakupi M, Ustalar-Ozgen S. Preemptive analgesic effects of midazolam and diclofenac in rat model. Bosn J Basic Med Sci. 2011;11(2):113-8.

26. Barrett AC, Smith ES, Picker MJ. Capsaicin-induced hyperalgesia and $\mu$ opioid-induced antihyperalgesia in male and female fischer 344 rats. J Pharmacol Exp Ther. 2003;307(1):237-45.

27. Bach-Rojecky L, Lackovic Z. Antinociceptive effect of botulinum toxin type a in rat model of carrageenan and capsaicin induced pain. Croat Med J. 2005:46(2):201-8.

28. Wallace MDM, Schulteis PDG, Atkinson MDJH, Wolfson MAT, Lazzaretto MSD, Bentley H, Gouaux B, Abramson PDI. Dose-dependent effects of smoked cannabis on capsaicin-induced pain and hyperalgesia in healthy volunteers. Anesthesiology. 2007;107(5):785-96.

29. Di Marzo V, Bisogno T, Melck D, Ross R, Brockie H, Stevenson L, Pertwee R, De Petrocellis $L$. Interactions between synthetic vanilloids and the endogenous cannabinoid system. FEBS Lett. 1998;436(3):449-54.

30. Vogel Z, Barg J, Levy R, Saya D, Heldman E, Mechoulam R. Anandamide, a brain endogenous compound, interacts specifically with cannabinoid receptors and inhibits adenylate cyclase. J Neurochem. 1993;61(1):352-5.

31. Melck D, Bisogno T, De Petrocellis L, Chuang H-h, Julius D, Bifulco M, Di Marzo V. Unsaturated long-chain N-Acyl-vanillyl-amides (N-AVAMs): vanilloid receptor ligands that inhibit anandamide-facilitated transport and bind to CB1 cannabinoid receptors. Biochem Biophys Res Commun. 1999;262(1):275-84.

32. Hoffmann J, Supronsinchai W, Andreou AP, Summ O, Akerman S, Goadsby PJ. Olvanil acts on transient receptor potential vanilloid channel 1 and cannabinoid receptors to modulate neuronal transmission in the trigeminovascular system. Pain. 2012;153(11):2226-32.

33. De Petrocellis L, Guida F, Moriello AS, De Chiaro M, Piscitelli F, de Novellis V, Maione S, Di Marzo V. N-palmitoyl-vanillamide (palvanil) is a non-pungent analogue of capsaicin with stronger desensitizing capability against the TRPV1 receptor and anti-hyperalgesic activity. Pharmacol Res. 2011;63(4):294-9.

34. Koplas PA, Rosenberg RL, Oxford GS. The role of calcium in the desensitization of capsaicin responses in rat dorsal root ganglion neurons. J Neurosci. 1997;17(10):3525-37.

35. Mandadi S, Numazaki M, Tominaga M, Bhat MB, Armati PJ, Roufogalis BD. Activation of protein kinase $C$ reverses capsaicin-induced calcium-dependent desensitization of TRPV1 ion channels. Cell Calcium. 2004;35(5):471-8.

36. Xu H, Blair NT, Clapham DE. Camphor activates and strongly desensitizes the transient receptor potential vanilloid subtype 1 channel in a vanilloidindependent mechanism. J Neurosci. 2005;25(39):8924-37.

37. Morita A, Iwasaki Y, Kobata K, lida T, Higashi T, Oda K, Suzuki A, Narukawa M, Sasakuma S, Yokogoshi H, Yazawa S, Tominaga M, Watanabe T. 
Lipophilicity of capsaicinoids and capsinoids influences the multiple activation process of rat TRPV1. Life Sci. 2006;79(24):2303-10.

38. McNamara FN, Randall A, Gunthorpe MJ. Effects of piperine, the pungent component of black pepper, at the human vanilloid receptor (TRPV1). Br J Pharmacol. 2005;144(6):781-90.

39. Ursu D, Knopp K, Beattie RE, Liu B, Sher E. Pungency of TRPV1 agonists is directly correlated with kinetics of receptor activation and lipophilicity. Eur J Pharmacol. 2011;641(2-3):114-22.

40. Micevych PE, Yaksh TL, Szolcsanyi J. Effect of intrathecal capsaicin analogues on the immunofluorescence of peptides and serotonin in the dorsal horn in rats. Neuroscience. 1983;8(1):123-31.

41. Dickenson A, Hughes C, Rueff A, Dray A. A spinal mechanism of action is involved in the antinociception produced by the capsaicin analogue NE 19550 (olvanil). Pain. 1990;43(3):353-62.

42. Kedei N, Szabo T, Lile JD, Treanor JJ, Olah Z, ladarola MJ, Blumberg PM. Analysis of the native quaternary structure of vanilloid receptor 1. J Biol Chem. 2001;276(30):28613-9.

43. Yang L, Fujita T, Jiang C-Y, Piao L-H, Yue H-Y, Mizuta K, Kumamoto E. TRPV1 agonist piperine but not olvanil enhances glutamatergic spontaneous excitatory transmission in rat spinal substantia gelatinosa neurons. Biochem Biophys Res Commun. 2011;410(4):841-5.

44. Lee M-G, Weinreich $D$, Undem BJ. Effect of olvanil and anandamide on vagal C-fiber subtypes in guinea pig lung. Br J Pharmacol. 2005;146(4):596-603.

\section{Submit your next manuscript to BioMed Central} and we will help you at every step:

- We accept pre-submission inquiries

- Our selector tool helps you to find the most relevant journal

- We provide round the clock customer support

- Convenient online submission

- Thorough peer review

- Inclusion in PubMed and all major indexing services

- Maximum visibility for your research

Submit your manuscript at www.biomedcentral.com/submit

) Biomed Central 